\title{
Motion sickness diagnostic criteria: Consensus Document of the Classification Committee of the Bárány Society
}

\author{
Yoon-Hee Cha ${ }^{\mathrm{a}, 1, *}$, John F. Golding ${ }^{\mathrm{b}, 1}$, Behrang Keshavarz ${ }^{\mathrm{c}, \mathrm{d}, 1}$, Joseph Furman ${ }^{\mathrm{e}}$, Ji-Soo Kim ${ }^{\mathrm{f}}$, \\ Jose A. Lopez-Escamez ${ }^{\mathrm{g}, \mathrm{h}, \mathrm{i}}$, Måns Magnussonn, Bill J. Yates ${ }^{\mathrm{k}}$, Ben D. Lawson ${ }^{\mathrm{l}, 1}$, \\ Advisors: Jeffrey P. Staab ${ }^{\mathrm{m}}$ and Alexandre Bisdorff ${ }^{\mathrm{n}}$ \\ ${ }^{a}$ Department of Neurology, University of Minnesota, Minneapolis, MN, USA \\ ${ }^{\mathrm{b}}$ Psychology, School for Social Sciences, University of Westminster, London, UK \\ ${ }^{\mathrm{c}}$ Toronto Rehabilitation Institute - University Health Network, Toronto, ON, Canada \\ ${ }^{\mathrm{d}}$ Department of Psychology, Ryerson University, Toronto, ON, Canada \\ ${ }^{\mathrm{e}}$ Department of Otolaryngology, University of Pittsburgh, Pittsburgh, PA, USA \\ ${ }^{\mathrm{f}}$ Department of Neurology Seoul National University, Seoul, Republic of Korea \\ ${ }^{\mathrm{g}}$ Department of Surgery, Division of Otolaryngology, Universidad de Granada, Granada, Spain \\ ${ }^{\mathrm{h}}$ Otology and Neurotology Group CTS495, Department of Genomic Medicine, Centre for Genomics and Oncology \\ Research - Pfizer/Univ. de Granada/Junta de Andalucía (GENyO), PTS, Granada, Spain \\ ${ }^{\mathrm{i}}$ Department of Otolaryngology, Instituto de Investigación Biosanitaria ibs. GRANADA Hospital Universitario \\ Virgen de las Nieves, Granada, Spain \\ ${ }^{\mathrm{j} D e p a r t m e n t ~ o f ~ O t o r h i n o l a r y n g o l o g y, ~ L u n d ~ U n i v e r s i t y, ~ L u n d, ~ S w e d e n ~}$ \\ ${ }^{\mathrm{k}}$ Department of Otolaryngology, University of Pittsburgh, Pittsburgh, PA, USA \\ ${ }^{1}$ Naval Submarine Medical Research Laboratory, Naval Submarine Base New London, Groton, CT, USA \\ ${ }^{\mathrm{m}}$ Department of Psychiatry and Psychology, Mayo Clinic, Rochester, MN, USA \\ ${ }^{\mathrm{n}}$ Department of Neurology, Centre Hospitalier Emile Mayrisch, Esch-sur-Alzette, Luxembourg
}

Received 11 August 2020

Accepted 8 February 2021

\begin{abstract}
We present diagnostic criteria for motion sickness, visually induced motion sickness (VIMS), motion sickness disorder (MSD), and VIMS disorder (VIMSD) to be included in the International Classification of Vestibular Disorders. Motion sickness and VIMS are normal physiological responses that can be elicited in almost all people, but susceptibility and severity can be high enough for the response to be considered a disorder in some cases. This report provides guidelines for evaluating signs and symptoms caused by physical motion or visual motion and for diagnosing an individual as having a response that is severe enough to constitute a disorder.

The diagnostic criteria for motion sickness and VIMS include adverse reactions elicited during exposure to physical motion or visual motion leading to observable signs or symptoms of greater than minimal severity in the following domains: nausea and/or gastrointestinal disturbance, thermoregulatory disruption, alterations in arousal, dizziness and/or vertigo, headache and/or ocular strain. These signs and/or symptoms occur during the motion exposure, build as the exposure is prolonged, and eventually stop after the motion ends. Motion sickness disorder and VIMSD are diagnosed when recurrent episodes of
\end{abstract}

\footnotetext{
${ }^{1}$ Except for the first three authors and the last author, all authors are listed alphabetically.

${ }^{*}$ Corresponding author: Yoon-Hee Cha, Department of Neurology, University of Minnesota, Minneapolis, MN, USA. E-mail: ycha@umn.edu.
} 
motion sickness or VIMS are reliably triggered by the same or similar stimuli, severity does not significantly decrease after repeated exposure, and signs/symptoms lead to activity modification, avoidance behavior, or aversive emotional responses.

Motion sickness/MSD and VIMS/VIMSD can occur separately or together. Severity of symptoms in reaction to physical motion or visual motion stimuli varies widely and can change within an individual due to aging, adaptation, and comorbid disorders. We discuss the main methods for measuring motion sickness symptoms, the situations conducive to motion sickness and VIMS, and the individual traits associated with increased susceptibility. These additional considerations will improve diagnosis by fostering accurate measurement and understanding of the situational and personal factors associated with MSD and VIMSD.

\section{Introduction}

The Classification Committee of the Bárány Society was charged with establishing standardized international clinical diagnostic criteria for motion sickness and visually induced motion sickness (VIMS) and defining when these conditions constitute disorders. These criteria were developed by an international group of vestibular specialists, scientists, and therapists for the Bárány Society in order to promote a common reference frame across disciplines involved in the care of the general public and of individuals with high susceptibility to motion sickness or VIMS. Though a common phenomenon, sickness induced by physical motion of the person or visual motion can adversely affect otherwise healthy individuals and decrease safety in situations that require high levels of concentration. The establishment of these criteria recognizes that motion sickness and VIMS, while being normal physiologic responses, can have profound negative effects when symptoms are severe, and can sometimes be considered a motion sickness disorder (MSD) or visually induced motion sickness disorder (VIMSD).

\subsection{History}

Descriptions of motion induced sickness date back to $400 \mathrm{BCE}$, becoming more common as modes of transportation advanced with time. Ancient Greek texts mention symptoms of seasickness such as nausea, vomiting, faintness, difficulty concentrating, and lack of initiative, which are still considered valid today [1]. Theories to explain such reactions to motion evolved over the centuries from pre-scientific ideas to later explanations concerning the effects of inner ear overstimulation or disrupted multisensory integration [1-3]. It has long been known that the vestibular organs are implicated in seasickness [4] and that people without vestibular function are not susceptible to motion sickness, even during highly sickening sea conditions [5]. Modern interest in the mechanisms, treatment, and prevention of motion sickness grew dramatically in the early 20th century due to the unprecedented number of military troops being transported by sea, air, and land. The initiation of space travel in the 1960s further spurred interest in motion sickness research, fostering some of the assessment tools and countermeasures that are used today [6].

Motion sickness that is mainly caused by stimulation of the visual system, often in the absence of physical motion, has received increased recognition recently [7, 8]. Symptoms of VIMS were reported as early as the 19th century in the haunted swing amusement ride and documented during adaptation to visual rearrangement and subsequent readaptation to normal vision [9-11]. These early reports noted symptoms such as dizziness, nausea, and vertigo, each of which is still featured today in the most widely-used simulator sickness state questionnaire [12]. Modern scientific studies of VIMS were first documented in the 1950s in laboratory and military domains when optokinetic stimuli and flight simulators were found to cause motion sickness-like symptoms (nausea, dizziness, vertigo/disorientation, blurred vision, headache, and drowsiness) [13-17]. Due to recent technological advancements, visual displays and applications have become pervasive (surround theaters, vehicle simulators, virtual reality, augmented reality), making VIMS a common phenomenon.

\subsection{Theories}

Motion sickness and VIMS are polysymptomatic syndromes driven by the interaction between a specific stimulus and individual susceptibility. While there is no single, universally accepted theory of motion sickness or VIMS, several hypotheses exist 
concerning the evolutionary origins and immediate etiology of motion sickness and VIMS [6, 7, 17-21].

The sensory conflict/neural mismatch hypothesis of motion sickness is the most cited explanation. It posits that motion sickness is caused by a conflict between expected versus actual interactions among visual, vestibular, and somatosensory inputs $[6,18]$. This conflict can be due to dissonance among different sensory modalities, intra-vestibular mismatch between canal and otolith inputs, mismatch between current multisensory input versus multisensory calibrations acquired during past stimuli, and/ or a discrepancy between the perceived and actual orientation of the gravitational upright [19-22]. Motion sickness has also been hypothesized to be a by-product of the abnormal activation of vestibuloautonomic pathways by physical or apparent motion to which the human nervous system is unable to or has not had sufficient time to adapt [23, 24]. These theories predict that motion sickness will diminish with repeated exposure if the challenging motions are sufficiently within one's adaptive capacity and the internal model of expected sensory input recalibrates.

The toxin hypothesis of motion sickness is a variant of the sensory conflict theory which attempts to explain the evolutionary origins of the characteristic symptoms of motion sickness (e.g., nausea, vomiting) rather than the immediate cause of the motion sickness reaction during a given stimulus [25]. This hypothesis postulates that motion-induced vomiting is an accidental, modern (transportation-related) by-product of an ancient evolutionarily protective response to the neural effects of various toxins which are often associated with distortions of sensory input. Thus, sensory integration disturbances and neural effects are produced by modern motions which are similar to ancient responses triggered by poisoning (e.g., from spoiled meat, toxic plants, animal venom, or even intoxicants such as fermented fruit) [17]. A shared susceptibility to triggering the emetic pathway by different mechanisms is supported by the observation that individuals with high motion sickness susceptibility are more likely to suffer from nausea and vomiting from other causes, such as chemotherapy and actual toxins [26]. However, many tenets of the toxin hypothesis have been questioned and modified.

The direct evolutionary hypothesis posits that ancient physical or apparent motions existed that could have contributed directly to the evolution of aversive reactions, without the need for accidental coopting of a poison response via the neural effects of modern transportation [17]. Nevertheless, the direct poisoning hypothesis [17] posits that the body's poison response system shaped some of the signature motion sickness symptoms that emerged during the direct evolution of aversive reaction to certain ancient motions.

Finally, the possibility has been raised that motion sickness is simply an unfortunate structural consequence of the proximity of anatomical pathways that mediate vestibular signals with those that mediate nausea and vomiting without conferring any functional benefit to the individual $[27,28]$.

\section{Approach}

\subsection{Committee organization}

Members of the Classification Committee of the Bárány Society (CCBS) met in Berlin, Germany in March 2017 and proposed the creation of a subcommittee to develop criteria for motion sickness for the International Classification of Vestibular Disorders (ICVD). They selected a Chairperson (Y.H.C.) to choose subcommittee members who represented a broad range of subspeciality expertise and who came from three different continents. Subcommittee communication occurred through email and subsequent meetings. The CCBS met again to discuss its progress before the 30th Bárány Society meeting in Uppsala, Sweden in June 2018, and in Berlin, Germany in November 2019. Diagnostic criteria were developed through discussions among subcommittee members. Draft criteria were presented to the CCBS in November 2019 and then modified based on comments. A revised draft was made available for comment by the Bárány Society membership in January 2020. Further comments and concerns were addressed before publication.

\subsection{Selection of symptoms for criteria}

The diagnostic criteria described in this report are derived from a large body of studies that have categorized motion sickness symptoms and have contributed to the development of well-validated motion sickness metrics. The categorization of the symptoms of motion sickness and VIMS was initially driven by military and space exploration needs to include pre-vomiting symptoms. Vomiting, while objective, is usually a late sign of motion sickness and is impractical for assessing escalating severity of motion sickness and VIMS. The identification of 
earlier symptoms broadened the spectrum of severity of motion sickness and led to recognition of when interventions were needed to stop the progression of sickness. By the 1940s, some of the most common symptoms beyond obvious vomiting or retching were agreed upon by multiple authors (e.g., cold sweating, pallor), and a full diagnostic checklist containing multiple motion sickness symptoms was developed by the 1960s [29-31].

The three most influential multisymptom motion sickness state questionnaires are the following: 1) the Simulator Sickness Questionnaire/Motion Sickness Questionnaire (SSQ/MSQ) [12], 2) the Pensacola Diagnostic Index (PDI) (most-cited in [32], and fully matured in [31]), and 3) the Motion Sickness Assessment Questionnaire (MSAQ) [33]. The complete 28-item MSQ and the 16-items focused on simulator sickness that make up the SSQ portion have been cited more than any other motion sickness state questionnaires and are relevant to the development of other motion sickness scales (e.g. MSAQ [33], Misery Scale [34]). In order to form a more manageable and easily remembered set of criteria, however, the major items of the MSQ/SSQ and the PDI have been grouped. Cross-referencing the most agreed-upon symptoms across multiple formal motion sickness/VIMS diagnostic categorization efforts produced the motion sickness/VIMS criteria listed below and detailed in Tables 1-3.

\section{Diagnostic criteria}

\subsection{Motion sickness and visually induced motion sickness}

Motion sickness is diagnosed when the sickness inducing stimulus is physical motion of the person; visually induced motion sickness (VIMS) is diagnosed when the stimulus is visual motion. An acute episode of motion sickness/VIMS is sickness induced by physical motion/visual motion that meets Criteria A through D:

A. Physical motion of the person ${ }^{1}$ or visual motion $^{2}$ elicits sign(s) and/or symptom(s) in at least one of the following categories, experienced at greater-than-minimal severity:

1. Nausea and/or gastrointestinal disturbance ${ }^{3}$

2. Thermoregulatory disruption ${ }^{4}$

3. Alterations in $\operatorname{arousal}^{5}$
4. Dizziness and/or vertigo ${ }^{6}$

5. Headache and/or ocular strain ${ }^{7}$

B. Sign(s) and/or symptom(s) appear during motion and build as exposure is prolonged ${ }^{8}$

C. Sign(s) and/or symptom(s) eventually stop after cessation of motion ${ }^{9}$

D. Sign(s) and/or symptom(s) are not better accounted for by another disease or disorder ${ }^{10}$

COMMENTS: Nausea and/or gastrointestinal disturbance can include a feeling of sickness with an urge to vomit, actual vomiting, retching, epigastric/stomach discomfort/awareness, change in salivation and/or appetite, burping, or a desire to move bowels. Thermoregulatory disruption can include sweating/cold sweating, clamminess, flushing, warmth, and pallor. Alterations in arousal can include drowsiness, fatigue, tiredness, and difficulty concentrating. Dizziness and/or vertigo can include these symptoms as well as disorientation, faintness, and visual motion illusions. Headache and/or ocular strain can include head pain, head fullness, eyestrain, difficulty focusing, or blurred vision. Blurred vision can also occur in the context of vertigo. The presence of a greater number of signs and/or symptoms allows greater specificity that symptoms are due to motion sickness.

\section{NOTES:}

1. A variety of physical motion stimuli can trigger motion sickness. While highly susceptible people tend to be susceptible to multiple motion stimuli, susceptibility to one type of stimulus does not necessarily correlate with susceptibility to others for an entire group of people. Examples of sickening motion stimuli include:

a. Water transportation, e.g., ships, boats, rafts, submarines, floating, snorkeling, scuba-diving

b. Air transportation, e.g., airplanes, helicopters, hang-gliding, parasailing, skydiving, parabolic flight

c. Land transportation, e.g., cars, trains, trucks, buses, off-road vehicles (including armored vehicles), self-driving cars, and some forms of animal-based transportation (e.g., camels)

d. Amusement devices, e.g., amusement park rides, playground motion devices, certain swings or hammocks 
e. Swaying buildings, e.g., low frequency wind or tremor-induced sway, especially in tall buildings

f. Vestibular stimulation in laboratory settings, e.g., Coriolis cross-coupling, offvertical axis rotation (OVAR), horizontal or vertical low frequency linear oscillation, and certain stimuli aboard human centrifuges

g. Space travel, e.g., upon entering orbit or first returning to Earth

2. Visual stimulation may be presented via virtual/augmented reality devices, simulators, movies, computer monitors, dynamic video games, or optokinetic drums. Even some small mobile displays can be disturbing under certain conditions (e.g., display parallax wherein foreground and background move or when viewed while walking or riding in a vehicle). When visually-triggered motion sickness also includes physical motion, e.g., motion-based flight simulators, driving simulators, or ship simulators, the contributions of both forms of stimuli should be noted.

3. Many of these symptoms and others in the criteria have been formally defined $[12,17]$. Stomach awareness and discomfort are common early gastric manifestations of motion sickness. The unpleasant sensations can include the esophageal or epigastric areas. Nausea may be mild or severe. Though the probability of vomiting is generally related to the severity of nausea, vomiting may rarely occur at low or negligible levels of nausea without much warning in some situations, or in very susceptible people [35]. Prolonged mild or moderate nausea can occasionally lead to an 'avalanche' phenomenon in which symptoms rapidly escalate to vomiting [36]. If vomiting occurs during a severe stimulus, it generally happens within 60-minutes of the onset of other symptoms, such as moderate or severe nausea [23, 37]. Vomiting is not as common with VIMS as with physical motion, partially because affected individuals can close their eyes before symptoms become severe. Nausea and related symptoms should be distinguishable by the clinician from primary gastric disorders and anxiety.

4. When due to motion sickness, sweating is generally a 'cold' sweat that can accompany other autonomic signs and symptoms. The sweating is 'cold' because it occurs in the absence of a rise in ambient temperature, not because it is always experienced as cold clamminess. In fact, it is often preceded by a sudden warm sensation in the face, neck, and/or upper chest. Sweating due to motion sickness in a warm environment should be distinguishable from ambient thermal causes (e.g., by suddenness of onset). Pallor is almost always present in some combination prior to vomiting [38]. However, an individual's recollection concerning pallor depends upon others to mention it or for the individual to observe it (e.g., in a mirror). Therefore, a recollection of pallor should be weighed heavily by clinicians but failing to recollect the presence of pallor is inconclusive.

5. Symptoms such as fatigue, drowsiness, or difficulty concentrating are part of the full list of $28 \mathrm{SSQ} / \mathrm{MSQ}$ symptoms and are considered to be suggestive of the 'sopite' syndrome [39]. Several other symptoms related to poor mood or reduced motivation have been inferred to be sopite-related during prolonged motion tests [39], and symptoms such as fuzzy/foggyheaded, lazy/unmotivated, and relaxed have been endorsed by research participants recollecting situations involving mild motion [17, 40]. Fatigue due to motion sickness should be distinguishable from sleep deprivation, physical exhaustion, or other disorders causing lethargy.

6. When due to motion sickness, these symptoms should not be solely attributable to vestibular disorders, changes in atmospheric pressure, postural hypotension, or visual cliffs [41]. Feelings of vertigo or spinning can also be elicited without motion sickness during piloting an aircraft without good visual references or experiencing a visually induced illusion of selfmotion. When an episode of vertigo leads to overlapping symptoms with motion sickness, these symptoms are considered sequelae of the vertigo spell and not a separate motion sickness syndrome. However, clinicians should be aware of differences between the ICVD and the motion sickness literature, the latter of which established its symptom definitions prior to the ICVD. The ICVD defines dizziness as disturbed or distorted orientation without a sense of motion [42], whereas in motion sickness 
research, dizziness is not always defined or has a definition that does not exclude illusions of self-motion. Similarly, the ICVD defines vertigo as, "a sensation of self-motion when no self-motion is occurring or the sensation of distorted self-motion during an otherwise normal head movement," [42] whereas in motion sickness research, vertigo usually means a loss of orientation with respect to the vertical upright [12]. The ICVD definition of internal vertigo does not explicitly distinguish among illusions of angular motion, linear motion, or tilt. Applying the ICVD definition of vertigo to the motion sickness literature, vertigo certainly can be induced by motion stimuli which elicit motion sickness. The most widely used laboratory protocol for the controlled elicitation of severe motion sickness (Coriolis cross-coupling during constant velocity rotation in the dark) repeatedly elicits a temporary illusion of distorted self-tilt displacement (and an even greater illusion of self-velocity) during otherwise normal head movements. Similarly, illusions of velocity and displacement can be caused by high-speed turns, low-frequency horizontal linear oscillation, viewing large optokinetic fields, decelerating after non-pendular centrifugation, various flight illusions (e.g., leans, somatogravic, Gexcess), and terrestrial readaptation following spaceflight, most of which can cause motion sickness [41, 43]. For these reasons, it is best for clinicians not to assume that a report of frank vertigo is evidence against motion sickness having occurred in a person without vestibular pathology.

Visually induced dizziness (VID) is recognized as a sense of spatial disorientation caused by moving or visually complex stimuli and is time-locked to the stimulus, ie. the onset is immediate with the onset of the visual stimulus. Dizziness in VIMS is phenomenologically indistinguishable from VID, but the onset will often be delayed and build in intensity with continued exposure. While whole-field motion is known to readily elicit an illusion of selfmotion (called vection), this illusion is neither necessary nor sufficient for VIMS to occur [17]. Nevertheless, a large field moving in the roll (x-axis) of the head can cause a compelling sensation of self-motion consistent with vection [44].
7. Greater susceptibility to motion sickness and VIMS occurs in individuals with migraine or vestibular migraine (See section 4.5.1) but headaches triggered by motion are not necessarily migraine headaches [45]. Though motion sickness and VIMS symptoms typically resolve quickly after the motion stops, headache can persist until specifically treated. Headache may be more common and occur more frequently without nausea in VIMS than in motion sickness caused by physical motion. A secondary symptom, head fullness, is relevant as well, since it is a similar symptom that has emerged frequently in simulator or cybersickness studies. Eyestrain/discomfort, difficulty focusing, and visual blurring are particularly common symptoms of VIMS [7, 8]. Eye/visual symptoms should be distinguishable from visual overwork or ocular/visual disorders. Blurred vision may also accompany vertigo, and not always imply ocular dysfunction.

8. Symptoms that start immediately with movement or are maximal at the onset of motion should raise suspicion for a possible disorder (vestibular for physical motion, ocular or visual-vestibular for visual motion), an anxiety reaction, or an aversively conditioned response wherein past motion sickness has led to classical conditioning to the sight and smell of the situation. However, strong stimuli may induce symptoms quickly in very susceptible individuals. Continued exposure within the individual's adaptive capacity may also lead to habituation and eventual reduction of sickness.

9. Although some symptoms of motion sickness or VIMS may persist after termination of the stimulus, the onset of sickness symptoms must occur during the motion stimulus and not begin exclusively after the stimulus has ended. This distinguishes motion sickness from mal de débarquement syndrome, which only begins once the motion has ended and lasts for at least 48-hours [46].

10. Motion sickness and VIMS may co-occur and symptom severity may be exacerbated by the presence of ocular motility disorders, visualvestibular disorders, or vestibular disorders such as vestibular migraine, vestibular neuritis, or persistent postural perceptual dizziness. In these situations, both a diagnosis of motion sickness or VIMS and the contributing disorder should be made. 


\subsection{Motion sickness disorder and visually induced motion sickness disorder}

Motion sickness disorder (MSD) is diagnosed when the sickness inducing stimulus is physical motion; visually induced motion sickness disorder (VIMSD) is diagnosed when the stimulus is visual motion. MSD or VIMSD is diagnosed when Criteria A through $\mathrm{E}$ are met:

A. At least five episodes of motion sickness/VIMS triggered by the same or similar motion stimuli $^{1,2,3}$

B. Sign(s) and/or Symptom(s) are reliably triggered by the same or similar motion stimuli ${ }^{4}$

C. Sign(s) and/or Symptom(s) severity does (do) not significantly decrease after repeated exposure to the same or similar motion stimuli ${ }^{5}$

D. Sign(s) and/or Symptom(s) lead to one or more of the following behavioral or emotional responses ${ }^{6}$
a. Activity modification to reduce sickness $\operatorname{sign}(\mathrm{s}) / \mathrm{symptom}(\mathrm{s})$
b. Avoidance of the motion stimulus that trig- gers sickness
c. Aversive anticipatory emotions prior to exposure to the motion stimulus

E. Sign(s) and/or Symptom(s) are not better accounted for by another disease or disorder ${ }^{7}$

\section{COMMENTS:}

1. Probable MSD/VIMSD can be diagnosed if two to four episodes have occurred.

2. On a population level and in the absence of certain disorders that impact vestibular function (see Section 4.5) motion sickness susceptibility typically peaks during youth and adolescence and declines with age. Defining whether the symptoms refer to the $\leq 12$-year range or the $>12$-year range will help in accurate communication of current status and in determination of prognostic variables. Based on a simplified scoring system of the MSSQ, the Pearson correlation between recollected childhood (Part A) and adult motion sickness susceptibility (Part B) is $r=0.65[47,48]$.

\section{NOTES:}

3. Susceptibility to motion sickness or VIMS from one type of stimulus may not predict reactions to other disparate types of stimuli. Therefore, motion sickness and VIMS to each motion stim- ulus (e.g., airplanes, automobiles, boats, virtual reality systems, simulators) should be considered separately (see Notes $1 \& 2$, Section 3.1)

4. Sickness during exposure to one transportation situation tends to be one of the best predictors of sickness during subsequent exposure to a similar transportation situation [54]. Nevertheless, small craft are more susceptible to oscillations of the surrounding medium in which they travel, so an individual may feel sick on small boats but not large ships, or smaller propeller aircraft but not large jetliners. Moreover, the induction of VIMS may be specific to a particular headmounted virtual reality display, simulator, or viewing screen.

5. Susceptibility to motion sickness and VIMS usually declines with repeated exposures, with the rate of adaptation being dependent upon many factors including the strength or predictability of the initial stimulus, inherent susceptibility, aversive conditioning, and the individual's ability to adapt. The repeated triggering of sickness to the same stimulus signifies an inability to habituate and is a core feature of MSD and VIMSD. An exception is made for stimuli that are extremely severe and infrequent such as exposure to parabolic flight or very rough sea conditions.

6. The usual behavioral response to motion sickness or VIMS is to avoid the sickness-inducing motion stimulus or to shorten the duration of exposure, when possible. When neither is possible, negative anticipatory emotions or conditioned aversive responses (e.g., anticipatory nausea) may occur prior to exposure to the motion stimulus.

7. An individual may be diagnosed with MSD, VIMSD, or both.

\subsection{Motion sickness susceptibility and severity}

Intense interest in motion sickness and VIMS in the last century has led to the development of a number of severity and susceptibility scales. Several scales used for research purposes are presented, with common elements listed to show the overlap in queried symptoms (per Criteria 3.1 A). See Table 1 for multisymptom checklists of severity state [12,31-33] [40], Table 2 for single-answer severity state questionnaires $[49,50]$ [51-53] and Table 3 for retrospective scales for trait susceptibility [47, 48, 54]. 
Table 1

Multisymptom Checklist Motion Sickness Severity Questionnaires

\begin{tabular}{|c|c|c|c|}
\hline Known as & $\begin{array}{l}\text { Pensacola Diagnostic Index/Pensacola } \\
\text { Diagnostic Criteria/Modified Pensacola } \\
\text { Diagnostic Criteria }[31,32,40]\end{array}$ & $\begin{array}{l}\text { Simulator Sickness Questionnaire/ } \\
\text { Motion Sickness Questionnaire [12] }\end{array}$ & $\begin{array}{l}\text { Motion Sickness Assessment } \\
\text { Questionnaire [33] }\end{array}$ \\
\hline Shorthand & PDI/PDC/MPDC & SSQ/MSQ & MSAQ \\
\hline Year & $1968 / 1970 / 2014$ & 1993 & 2001 \\
\hline Main Stimuli & $\begin{array}{l}\text { Initially validated during: rotation room (free } \\
\text { movement, Dial Test, automated Coriolis } \\
\text { cross-coupling), Active/voluntary } \\
\text { Coriolis cross-coupling } \\
\text { Also used in: low-frequency oscillation, z-axis } \\
\text { recumbant rotation, simulators, spaceflight, } \\
\text { parabolic flight, optokinetic drums, } \\
\text { virtual reality, etc. }\end{array}$ & $\begin{array}{l}\text { SSQ: initially validated in stationary } \\
\text { and moving flight simulators } \\
\text { Also used in: virtual reality, optokinetic drums, etc. } \\
\text { SSQ/MSQ: developed mainly for sea sickness; } \\
\text { Also used in various lab motions, spaceflight, etc } \\
\text { parabolic flight, virtual reality, etc. }\end{array}$ & $\begin{array}{l}\text { Initially validated during: optokinetic drum } \\
\text { Also used in Coriolis cross-coupling, } \\
\text { driving simulator, different vessels at sea, }\end{array}$ \\
\hline Severity Level & $\begin{array}{l}\text { Most symptoms originally scored none- } \\
\text { minimal-minor-major. }\end{array}$ & None-slight-moderate-severe & $1-9(1=$ not at all, $9=$ severely $)$ \\
\hline $\begin{array}{l}\text { Multisymptom } \\
\text { Cluster Names }\end{array}$ & $\begin{array}{l}\text { No formal subfactors, but the following } \\
\text { symptoms are grouped as one severity } \\
\text { continuum in the original PDI: epigastric } \\
\text { awareness/discomfort, minimal, moderate, } \\
\text { major nausea, vomiting/retching }\end{array}$ & $\begin{array}{l}\text { Oculomotor }(\mathrm{O}) \\
\text { Disorientation }(\mathrm{D}) \\
\text { Nausea }(\mathrm{N})\end{array}$ & $\begin{array}{l}\text { Gastrointestinal }(\mathrm{G}) \\
\text { Central }(\mathrm{C}) \\
\text { Peripheral }(\mathrm{P})\end{array}$ \\
\hline Symptoms Queried & & $\begin{array}{l}\text { Below are } 16 \text { SSQ symptoms }+12 \\
\text { more comprising the full } S S Q / M S Q\end{array}$ & \\
\hline $\begin{array}{l}\text { Nausea, } \\
\text { Gastrointestinal } \\
\text { Distburbance }\end{array}$ & $\begin{array}{l}\text { Nausea } \\
\text { Vomiting/Retching } \\
\text { Epigastric awareness; Epigastric discomfort } \\
\text { (assessed separately but neither counted } \\
\text { towards severity score in original PDI) } \\
\text { Increased Salivation }\end{array}$ & $\begin{array}{l}\text { Nausea (N,D) } \\
\text { Vomiting (on full MSQ) } \\
\text { Stomach awareness (N) (but defined } \\
\text { as discomfort short of nausea) } \\
\text { Decreased/Increased appetite (two items on } \\
\text { full MSQ) } \\
\text { Burping (N) } \\
\text { Desite to move bowels (on full MSQ) } \\
\text { Increased salivation (N) } \\
\text { Decreased salivation (on full MSQ) }\end{array}$ & $\begin{array}{l}\text { Nausea }(G) \\
\text { Queasy }(G) \\
\text { As if may vomit }(G) \\
\text { Sick to stomach }(G)\end{array}$ \\
\hline $\begin{array}{l}\text { Thermoregulatory } \\
\text { Disruption }\end{array}$ & $\begin{array}{l}\text { Cold sweating } \\
\text { Flushing/warmth } \\
\text { Pallor }\end{array}$ & Sweating $(\mathrm{N})$ & $\begin{array}{l}\text { Sweaty }(\mathrm{P}) \\
\text { Clammy/Cold sweat }(\mathrm{P}) \\
\text { Hot/warm }(\mathrm{P})\end{array}$ \\
\hline
\end{tabular}


Table 1

(Continued)

\begin{tabular}{|c|c|c|c|}
\hline Known as & $\begin{array}{l}\text { Pensacola Diagnostic Index/Pensacola } \\
\text { Diagnostic Criteria/Modified Pensacola } \\
\text { Diagnostic Criteria }[31,32,40]\end{array}$ & $\begin{array}{l}\text { Simulator Sickness Questionnaire/ } \\
\text { Motion Sickness Questionnaire [12] }\end{array}$ & $\begin{array}{l}\text { Motion Sickness Assessment } \\
\text { Questionnaire [33] }\end{array}$ \\
\hline $\begin{array}{l}\text { Alterations } \\
\text { in Arousal }\end{array}$ & Drowsiness & $\begin{array}{l}\text { Drowsiness (on full MSQ) } \\
\text { Fatigue (O) } \\
\text { Depression (on full MSQ) } \\
\text { Difficulty concentrating (N,O) } \\
\text { Confusion (on full MSQ) } \\
\text { Boredom (on full MSQ) } \\
\end{array}$ & $\begin{array}{l}\text { Drowsy (S) } \\
\text { Tired/fatigued (S) } \\
\text { Annoyed/irritated (S) }\end{array}$ \\
\hline $\begin{array}{l}\text { Dizziness/ } \\
\text { Vertigo }\end{array}$ & $\begin{array}{l}\text { Dizziness (two items for eyes } \\
\text { open/closed) }\end{array}$ & $\begin{array}{l}\text { Dizziness (D) (two items: } \\
\text { eyes open/closed) Vertigo (D) }\end{array}$ & $\begin{array}{l}\text { Dizzy }(\mathrm{C}) \\
\text { Spinning }(\mathrm{C})\end{array}$ \\
\hline $\begin{array}{l}\text { Headachel } \\
\text { Ocular }\end{array}$ & Headache & $\begin{array}{l}\text { Headache }(\mathrm{O}) \\
\text { Fullness of head (D) } \\
\text { Blurred vision (O,D) } \\
\text { Eystrain }(\mathrm{O}) \\
\text { Difficulty focusing (O) } \\
\text { Visual illusions of movement (when not in } \\
\text { device or vehicle) (on full MSQ) }\end{array}$ & \\
\hline General & & General discomfort $(\mathrm{N}, \mathrm{O})$ & $\begin{array}{l}\text { Faintlike }(\mathrm{C}) \\
\text { Lightheaded (C) } \\
\text { Uneasy (S) (under Sopite cluster but dictionary } \\
\text { defines similarly to general discomfort) }\end{array}$ \\
\hline
\end{tabular}


The subcommittee recommends that each scale be used based on its specific advantages to the research question or clinical application, e.g. the Motion Sickness Susceptibility Questionnaire (MSSQ-Short) form to retrospectively estimate general motion sickness trait susceptibility [48], the first 16 items of the Simulator Susceptibility Questionnaire (SSQ) for estimating state VIMS, and the full list of 28 SSQ/MSQ symptoms for estimating state motion sickness [12].

While motion sickness can be induced in nearly all people with a sufficiently strong stimulus, there are individuals at the extremes of the population distribution of susceptibility. The distribution curve of recollections of past susceptibility is linear up to about the $75^{\mathrm{Th}}$ percentile of susceptibility and flattens out on the high end of scores, e.g., on the MSSQ-Short form, out of a total possible score of 54, a score of $11=50$ th percentile, $19=75$ th percentile, $27=90$ th percentile, and $31=95$ th percentile, indicating that only a small proportion of people are severely susceptible to motion sickness, i.e. $90 \%$ of people score 0-27 while $10 \%$ of people score 28-54 on the MSSQ scale [47]. Norms may be different depending on the demographic traits of the population sampled, which should be considered when working with nonrepresentative populations [55, 56].

Though highly susceptible people tend to develop motion sickness in response to more than one kind of stimulus, susceptibility to motion sickness in individuals of normal susceptibility is not a strong predictor of susceptibility to VIMS. Prediction could be partially limited by large individual variability in symptom type and progression [56]. Nausea and vomiting are typically less common in VIMS, whereas ocular motor issues (e.g., eyestrain, blurred vision) and headache are more common in VIMS than in motion sickness. Additionally, older adults are more susceptible to VIMS but not to motion sickness than younger adults [7, 17, 57].

The frequency and severity of motion sickness events can be mitigated by reducing exposure to sickness-inducing stimuli (e.g., avoidance or cessation), modifying behavior during exposure to reduce the stimulus impact (e.g., limiting head movements), taking medications prior to exposure, maximizing helpful Earth-referenced cues (e.g., viewing of the outside world), or by engaging in measured amounts of motion exposure to induce habituation. Interventions which have been tried include habituation exercises (eye-head motion and repeated exposure) [23], pharmacologic pretreatments (anti-muscarinic, anti-histaminic, anticholinergic medications) [58], non-pharmacological treatments (music, smells) [59], and behavioral techniques (breathing exercises, meditation) [60]. It is common to hear about ginger or acupressure as motion sickness countermeasures, but the empirical evidence for these interventions is mixed [61-65]. The effectiveness of these methods varies widely, with the greatest benefit derived from adaptation, medications, and modifying behavior during exposure. Habituation is often stimulus-specific, however, and may not generalize across motion situations.

\subsection{MSD and VIMSD impact}

Motion sickness that is mild, easily avoidable, or has no functional impact is common among individuals with normal vestibular function and should not be considered a disorder. However, motion sickness susceptibility that affects activities of daily living such as meeting basic transportation needs or fulfilling obligations to family, employers, or social contacts can have physical and mental health consequences. Even in otherwise healthy individuals, motion sickness can reduce work or school productivity and decrease social engagement through direct effects from being ill, avoidance of sickness-inducing activities, or sedation induced by motion or by pharmacological motion sickness remedies [27, 66, 67]. Nausea, lethargy, and drowsiness can shift attention away from critical tasks, while vomiting can lead to dehydration or aspiration $[39,68]$.

Formal disability scales can be paired with existing motion sickness or VIMS scales to quantify disability due to MSD or VIMSD. As an example, the Sheehan Disability Scale quantifies impact on work, family, or social function on a 10-point scale along with a query of loss of work time or productivity due to symptoms [69]. Alternatively, a basic impact assessment that queries whether work, social, family, or travel difficulties are experienced (Yes or No) due to symptoms can be used as a quick assessment, e.g., the Social life and Work Impact of Dizziness short form adapted for motion sickness [70, 71].

In most cases, education, exposure minimization, avoidance of exacerbating behaviors, short-term use of anti-motion sickness medications, or simple habituation exercises beforehand may be employed to reduce morbidity. Even if motion sickness or VIMS does not constitute a disability, it should be recognized as a clinical entity that deserves medical attention. 
Table 2

Single Answer Motion Sickness Severity Scales

\begin{tabular}{|c|c|c|c|}
\hline Known as & $\begin{array}{l}\text { Illness Rating } \\
{[49,50]}\end{array}$ & $\begin{array}{l}\text { Misery Scale } \\
{[51,52]}\end{array}$ & $\begin{array}{l}\text { Fast Motion } \\
\text { Sickness Scale [53] }\end{array}$ \\
\hline Shorthand & IR & MISC & FMS \\
\hline Year & $1992 / 2004$ & $2005 / 2011$ & 2011 \\
\hline Main Stimuli & $\begin{array}{l}\text { Initially validated in: Low frequency } \\
\text { motion/cross-coupled motion/Car; } \\
\text { Several other stimuli since }\end{array}$ & $\begin{array}{l}\text { Initially validated in: Motion } \\
\text { simulator/head mounted display; } \\
\text { Several other stimuli since }\end{array}$ & $\begin{array}{l}\text { Initially validated in: passive visual } \\
\text { simulations of driving and } \\
\text { rollercoasters; Several other stimuli since }\end{array}$ \\
\hline Severity Levels & $\begin{array}{l}0=\text { no symptoms }{ }^{\dagger} \\
1=\text { any symptoms, however slight* } \\
2=\text { mild symptoms* } \\
3=\text { mild nausea } \\
4=\text { mild to moderate nausea } \\
5=\text { moderate nausea but can continue } \\
6=\text { moderate nausea and want to stop } \\
{ }^{*} \text { E.g., stomach awareness; } \\
\text { other unspecified symptoms }\end{array}$ & $\begin{array}{l}0=\text { no problems } \\
1=\text { uneasiness }^{*} \\
2=\text { vague }^{* *} \\
3=\text { slight }^{* *} \\
4=\text { fairly }^{* *} \\
5=\text { severe }^{* *} \\
6=\text { slight nausea } \\
7=\text { fair(ly) nausea } \\
8=\text { severe nausea } \\
9=\text { retching } \\
10=\text { vomiting }\end{array}$ & $\begin{array}{l}0=\text { no sickness } \\
20=\text { frank sickness }\end{array}$ \\
\hline $\begin{array}{l}\text { Individual Symptoms } \\
\text { Implicitly Contributing } \\
\text { to Overall Score }\end{array}$ & & $\begin{array}{l}\text { ** Dizziness, warmth, headache, } \\
\text { stomach awareness, sweating, } \\
\text { other unspecified symptoms }\end{array}$ & $\begin{array}{l}\text { No individual symptoms tracked, } \\
\text { but subjects instructed to focus on } \\
\text { nausea, stomach problems, } \\
\text { and general discomfort } \\
\text { while ignoring other symptoms } \\
\text { (e.g., fatigue, dizziness, oculomotor) }\end{array}$ \\
\hline \multirow[t]{2}{*}{$\begin{array}{l}\text { Nausea, } \\
\text { Gastrointestinal } \\
\text { Distburbance }\end{array}$} & Nausea & $\begin{array}{l}\text { Nausea } \\
\text { Retching } \\
\text { Vomiting } \\
\text { Salivation }\end{array}$ & $\begin{array}{l}\text { (Nausea) } \\
\text { (Frank sickness) } \\
\text { (Stomach problems) }\end{array}$ \\
\hline & Stomach awareness & $\begin{array}{l}\text { Stomach awareness } \\
\text { Burping }\end{array}$ & \\
\hline $\begin{array}{l}\text { Thermoregulatory } \\
\text { Disruption }\end{array}$ & & $\begin{array}{l}\text { Sweating } \\
\text { Warm }\end{array}$ & \\
\hline $\begin{array}{l}\text { Alterations } \\
\text { in Arousal }\end{array}$ & & $\begin{array}{l}\text { Tiredness } \\
\text { Yawning }\end{array}$ & \\
\hline Dizziness/Vertigo & & Dizziness & \\
\hline Headache/Ocular & & $\begin{array}{l}\text { Headache } \\
\text { Blurred vision }\end{array}$ & \\
\hline Other & & Uneasiness & General discomfort \\
\hline
\end{tabular}


Table 3

Retrospective Motion Sickness Trait Susceptibility Scales

\begin{tabular}{lll}
\hline Known as & $\begin{array}{l}\text { Pensacola Motion History } \\
\text { Questionnaire [54] }\end{array}$ & $\begin{array}{l}\text { Motion Sickness } \\
\text { Susceptibility Questionnaire } \\
\text { (Long/Short) [47, 48] }\end{array}$ \\
\hline Shorthand & MHQ & $\begin{array}{l}\text { MSSQ; MSSQ-S; } \\
\text { (54 items; later shortened to 18) }\end{array}$ \\
\hline Year & 1990 & $1998 / 2006$ \\
\hline $\begin{array}{l}\text { Motion type queried } \\
\text { Components }\end{array}$ & Physical motion & $\begin{array}{l}\text { Physical motion } \\
\text { Part A Child (<12yrs) } \\
\text { Part B Adult (last 10 yrs) }\end{array}$ \\
\hline & $\begin{array}{l}\text { Queries incidence of 12 symptoms in 14 situations. } \\
\text { The 12 symptoms include: vomiting, nausea, } \\
\text { stomach awareness, increased salivation, } \\
\text { dizziness, drowsiness, sweating, pallor, vertigo, } \\
\text { awareness of breathing, headache, or other. }\end{array}$ & $\begin{array}{l}\text { nauseated during each of 9 situations } \\
\text { (Long version also queries } \\
\text { amount of exposure) }\end{array}$ \\
\hline
\end{tabular}

\section{Motion sickness clinical features}

\subsection{Prevalence}

The prevalence of motion sickness in childhood has been estimated at $35-43 \%$ prior to puberty and $25 \%$ in young adults; it is a frequent problem in $14 \%$ of adults younger than 30 years old and $7 \%$ of adults 61 years old or older [72-74]. The prevalence of VIMS ranges widely depending on the stimulus type and the visual content, with rates varying from $1 \%$ [75] to $60 \%$ [76] to $80-95 \%[77,78]$.

\subsection{Demographics}

\subsubsection{Age}

Susceptibility to motion sickness changes with age. Infants are resistant to motion sickness until about age 2 , after which point motion sickness susceptibility rises, peaking between the ages of 7-12 years, and declining thereafter through adulthood [19, $72,79]$. Susceptibility gradually continues to decline with age but may increase in a small proportion of individuals [27].

An increase in susceptibility to VIMS as a factor of age has been well-documented, with older adults reporting more VIMS than younger adults [55, 80, 81]. Prevalence estimates should consider that people might self-restrict their behavior and avoid situations that provoke motion sickness if they are aware of their elevated susceptibility.

\subsubsection{Sex}

The evidence of sex differences in motion sickness is mixed. Only $50 \%$ of the studies in the literature have found women to be significantly more susceptible to motion sickness [17], with estimates varying among studies depending on stimulus type, endpoint studied, age, ethnicity, and hormonal status [47, 74, 82-86]. Sex differences in motion sickness are seen more frequently in survey studies than in controlled laboratory studies and more commonly in older studies than recent ones [17]. Even among authors positing a sex difference, the estimated effect of sex is only about one-third that of age [87, 88]. Secondary hormonal factors such as the use of oral contraceptives, menstruation, pregnancy, and cortisol levels correlate with motion sickness susceptibility in women, which further complicate the association [87, $89,90]$.

Sex differences in VIMS have been observed in some studies [81, 91-93], but it remains unclear whether such observations are due to women being more open about reporting than men, better at introspecting than men, or having less experience with motion than men, among several other confounding reasons [17, 92]. A meta-analysis failed to detect any sex differences in VIMS due to virtual reality (VR) usage [94] while another study [95] concluded that VIMS sex differences in VR may be accounted for by a non-sex-specific variable such as difficulty in fitting the VR properly to people with smaller interpupillary distance. A variety of other factors unrelated to sex might affect occurrence of VIMS, including the person's innate size of field of view, video game experience, and passive restraints [96-98]. Overall, the case is weak for differences in VIMS that are specific to biological male vs. female birth category.

\subsubsection{Race and ethnicity}

Studies that assessed motion sickness susceptibility by questionnaire, rotation of the body with head pitching, and exposure to optokinetic drums have reported heightened susceptibility in people of Asian descent compared to European or African descent 
$[82,99]$. These differences persist in American-born children of Asian parents, supporting at least a partial heritable component to motion sickness susceptibility [99].

Further controlled studies of the ethnic, racial, or cultural components to motion sickness are needed. Generalizations concerning these features which could influence decisions about patient care or occupational status should be treated with caution.

\subsection{Genetic}

Heritability for motion sickness (in women) shows a 0.69 concordance in monozygotic twins and 0.44 concordance in dizygotic twins for childhood motion sickness, yielding a heritability estimate of 70\% [72]. A large genome-wide association study involving 80,494 individuals with carsickness found 35 single nucleotide variants at genome-wide significant levels. The top ten genes involved in these regions included: PVRL3, GPD2, ACO1, AUTS2, GPR26, UBE2E2, CBLN4, MUTED, LINGO2 and CPNE4 [74]. A genetic risk score using the number of risk alleles found on each individual for these 35 variants could be used to anticipate motion sickness susceptibility. These genes involve a wide variety of functions such as brain, eye, and ear development and even insulin resistance. Some of these loci overlap with genes in individuals who experience dizziness, post-operative nausea and vomiting, altitude sickness, morning sickness, indigestion to dairy, and headache after red wine [74].

\subsection{Other modifying factors}

Other modifying factors may include baseline autonomic tone, glucose levels, and aerobic fitness [100-102]. It is difficult to predict how these numerous factors, in combination, ultimately impact susceptibility in an individual, however.

\subsection{Associated syndromes}

\subsubsection{Migraine}

Symptoms of migraine and motion sickness overlap in many respects, e.g., nausea, stomach awareness, and headache [84, 103]. Motion sickness is self-reported in at least $50 \%$ of migraine headache sufferers with motion sickness in childhood correlating with eventual development of migraine headaches in adolescence and adulthood [47, 104, 105]. These associations suggest that neural pathways for nausea and emesis are particularly sensitive in individuals with migraine [47]. Scalp tenderness and nausea during optokinetic stimulation increase more for those who experience migraine than for those who do not [106]. Motion sickness induced by OVAR is especially intense in individuals with migraine [45]. This type of motion sickness may be blunted by rizatriptan, a migraine abortive medication [107, 108]. In contrast, VIMS does not appear to be mitigated by pre-treatment with rizatriptan [109]. Individuals with migraine headaches experience both motion sickness and VIMS to a higher degree than those without migraine, but the correlation between motion sickness and VIMS in this group is weak [110].

\subsubsection{Structural vestibular disorders}

Loss of peripheral vestibular function significantly raises the threshold for motion sickness but the role of a functioning vestibular system for VIMS is less clear [45, 111-113]. Patients with chronic stable vestibular loss (unilateral and bilateral) report less motion sickness on clinical motion sickness ratings than healthy controls. In comparison, patients with benign paroxysmal positional vertigo fail to show a significant difference in motion sickness susceptibility [79]. Patients with vestibular neuritis can experience either an increase or a decrease in motion sickness susceptibility after the onset of their disorder, with increased susceptibility in uncompensated cases [45, 57]. Two studies have shown that individuals with Ménière's disease are more susceptible to motion sickness than healthy controls but are not as susceptible as those with migraine or vestibular migraine $[114,115]$. A significant correlation has not been found between the degree of caloric asymmetry in vestibular patients and scores on a clinical motion sickness questionnaire. In contrast, patients with vestibular disorders without vestibular loss report higher degrees of motion sickness than controls [45, 104]. About 10-minutes of laboratory motion exposure has been shown to distinguish the susceptibility of individuals with different vestibular disorders (vestibular neuritis, bilateral vestibulopathy, vestibular migraine) [45].

\section{Motion sickness laboratory examinations}

Motion sickness may be induced in laboratory settings with approximately $38 \%$ of the variability in motion sickness in operational settings being explained by an individual's response to provocative laboratory motion tests [54]. Most of these 
established motion sickness tests are not used for clinical diagnosis, however. Correlations between the MSSQ and laboratory-induced nausea by crosscoupled stimulation have been reported to be between 0.14 and 0.58 , with generally higher correlations seen for vertical translational oscillations than horizontal oscillations [47]. Of the three translational planes of motion, motion directions with respect to the gravity vector (e.g. Earth referenced vertical versus horizontal) are equivalent in their potential to cause motion sickness. However, motions through the body-referenced X- or Y- axes (for example, foreaft or side-to-side motion if upright, respectively) are more provocative than through the body-referenced Z-axis (e.g., up-down through the long axis of the head-body) [116]. In other words, motions in horizontal and vertical planes (Earth referenced) have the same nauseogenic potential, but changing the direction of motion with respect to the $\mathrm{X}$ and $\mathrm{Y}$ head-body axes is approximately twice as sensitive in producing motion sickness as the head-body Z-axis.

An area of controversy is whether a smaller phase lead of the vestibulo-ocular reflex (VOR), which indicates enhanced velocity storage, is related pathophysiologically to motion sickness susceptibility, as found in some laboratories [116-120] but not others $[88,107]$. The mixed findings may relate to the degree of habituation to the motion stimulus [121]. It has been proposed that the absolute value of the VOR may not be the relevant marker of motion sickness susceptibility, but rather the ability to modify the VOR in response to varying motion sickness-inducing stimuli $[27,88]$. The relationship between motion sickness susceptibility and adaptability of vestibular responses has also been supported by lower cervical vestibular evoked myogenic potential (VEMPS) thresholds correlating with the ability to habituate to seasickness; this may be attributable to the wider potential range of adaptive responses to motion stimuli with lower VEMP thresholds [122].

\section{Differential diagnosis}

Because motion sickness susceptibility in a healthy person generally declines with age, an adult presenting with increasing susceptibility to motion should be evaluated for underlying causes of a lowered threshold for motion sickness. This evaluation may include an assessment for vestibular disorders, migraine, endocrine abnormalities, ocular misalignment, and other central nervous system disorders. Head motion- induced discomfort (when not undergoing passive whole-body motion) should be suspected as being secondary to an uncompensated vestibular asymmetry and evaluated with vestibular laboratory testing, unless such discomfort is directly related to the aftereffects of prolonged adaptation to motion (e.g., return to land after a voyage at sea). Similarly, abrupt changes in VIMS should prompt careful evaluations for ocular and ocular motility problems. Clinicians should be aware that head motion during certain types of uncompensated vestibular pathology or by healthy persons during challenging motions or within unusual force environments (such as space) can each elicit similar symptoms of nausea, headache, dizziness, vertigo, oscillopsia, or visual blurring, so these symptoms cannot be assumed to definitively differentiate between vestibular pathology and motion sickness without further inquiry concerning when the symptoms appeared (e.g., relative to the last motion experience), under what conditions they appeared (e.g., the type and duration of the motion experience), and what additional symptoms were present [43]. Finally, while a motion sickness disorder would be more strongly suspected in a younger person scoring high on the MSSQ or a VIMS disorder in an older individual scoring high on the SSQ, individual variability in motion sickness and VIMS susceptibility is high, so clinicians should be cautious not to over-generalize from demographical findings.

\section{Future directions}

The presentation of these criteria for motion sickness acknowledges that there are still critical information gaps to be filled in order to determine a clear demarcation between motion sickness and VIMS as normal human responses to motion stimuli versus these responses representing a disorder. The difficulty in determining this distinction in no small part lies in the large number of variables that contribute to inherent (trait) susceptibility, comorbidity, and variability of the stimulus each person experiences.

A challenge in motion sickness and VIMS research has been the rapid technological advancements in transportation and entertainment options that have created an environment of increasing motion stimuli in both novelty and number [123]. It remains to be determined whether human beings may be able to push current boundaries of motion tolerance through enhanced habituation exercises, 
helpful Earth-referenced sensory cues, manipulation of vestibular input, cognitive enhancement techniques, pharmacological therapies, or noninvasive brain stimulation methods. Prediction of susceptibility based on demographics, hormonal rhythms, genetics, and physiological status may lead to optimization of environments that reduce stimulus intensity and morbidity. Toward those ends, criteria for motion sickness/VIMS and MSD/VIMSD have been proposed here to promote clearer communication among clinicians and investigators. These criteria are expected to evolve as data on epidemiology, natural history, biomarkers, and assessments of future health consequences are methodically acquired.

\section{Acknowledgements and disclaimers}

The working meetings for the International Classification of Vestibular Disorders (ICVD) are financially supported by the International Bárány Society and by Neuro + e.V., Berlin, Germany, a nonprofit association for neurological research. We thank members of the Bárány Society for reviewing the manuscript prior to publication. The views in this manuscript are those of the authors and do not reflect the official policy or position of the Department of the Navy, Department of Defense, nor the U.S. Government. This work was assisted by an employee of the U.S. Government (Dr. Lawson) as part of his official duties. Title 17, U.S.C., $§ 105$ provides that "copyright protection under this title is not available for any work of the U.S. Government.'

\section{References}

[1] D. Huppert, J. Benson and T. Brandt, A Historical View of Motion Sickness-A Plague at Sea and on Land, Also with Military Impact, Front Neurol 8 (2017), 114.

[2] E. Darwin, Zoonomia, or The Laws of Organic Life, Volume I : Second Edition. Printed for J. Johnson, St. Paul's Church-Yard, London, (1796)

[3] J.A. Irwin, The pathology of sea sickness, The Lancet 118 (1881), 907-909.

[4] W. James, The sense of dizziness in deaf-mutes, Am Ann Deaf 28 (1883), 102-117.

[5] R.S. Kennedy, A. Graybiel, R.C. McDonough and D. Beckwith, Symptomatology under storm conditions in the North Atlantic in control subjects and in persons with bilateral labyrinthine defects, Acta Oto-laryngol 66 (1968), 533-540.

[6] J.T. Reason and J.J. Bland, Motion Sickness, London, New York, San Francisco, 1975.
[7] B. Keshavarz, H. Hecht and B.D. Lawson, Visuallyinduced motion sickness: Causes, characteristics, and countermeasures. Handbook of virtual environments: Design, implementation, and applications, 2nd Edition. New York, NY: CRC Press, an imprint of Taylor \& Francis Group, LLC. (2014), 647-698.

[8] L.J. Hettinger and G.E. Riccio, Visually induced motion sickness in virtual environments, Presence-Teleop Virt 1 (1992), 306-310.

[9] R.W. Wood, The 'Haunted Swing' illusion, Psychol Rev 2 (1895), 277-278.

[10] G.M. Stratton, Some preliminary experiments on vision without inversion of the retinal image, Psychol Rev 3 (1896), 611-617.

[11] G.M. Stratton, Vision without inversion of the retinal image, Psychol Rev 4 (1897), 341-360.

[12] R. Kennedy, N. Lane, K. Berbaum and M. Lilienthal, Simulator sickness questionnaire: An enhanced method for quantifying simulator sickness, Int $J$ of Aviat Psychol 3 (1993), 203-220.

[13] G.H. Crampton and F.A. Young, The differential effect of a rotary visual field on susceptibles and nonsusceptibles to motion sickness, J Comp Physiol Psychol 46 (1953), 451-453.

[14] R. Kennedy, G. Allgood, B. Van Hoy and M. Lilienthal, Motion sickness symptoms and postural changes following flights in motion-based flight trainers, $J$ Low Freq Noise, Vib 6 (1987), 147-154.

[15] R.S. Kennedy, M.G. Lilienthal, K.S. Berbaum, D.R. Baltzley and M.E. McCauley, Simulator sickness in U.S. Navy flight simulators, Aviat Space Envir Md 60 (1988), 10-16.

[16] D.R. Baltzley, R.S. Kennedy, K.S. Berbaum, M.G. Lilienthal and D.W. Gower, The time course of postflight simulator sickness symptoms, Aviat Space Envir Md 60 (1989), 1043-1048.

[17] B.D. Lawson, Motion sickness symptomatology and origins. Handbook of virtual environments: Design, implementation, and applications, 2nd Edition. New York, NY: CRC Press, an imprint of Taylor \& Francis Group, LLC. (2014), 531-600.

[18] J.T. Reason, Motion sickness adaptation: A neural mismatch model, J R Soc Med 71 (1978), 819-829.

[19] J.F. Golding, Motion sickness susceptibility, Auton Neurosci-Basic 129 (2006), 67-76.

[20] C.M. Oman, Motion sickness: A synthesis and evaluation of the sensory conflict theory, Can J Physiol Pharm $\mathbf{6 8}$ (1990), 294-303.

[21] J.E. Bos and W. Bles, Modelling motion sickness and subjective vertical mismatch detailed for vertical motions, Brain Res Bull 47 (1998), 537-542.

[22] F.E. Guedry and A.J. Benson, Coriolis cross-coupling effects: disorienting and nauseogenic or not? Aviat Space Envir Md 49 (1978), 29-35.

[23] R. Kennedy, K. Stanney and W. Dunlap, Duration and exposure to virtual environments: Sickness curves during and across sessions, Presence-Teleop Virt 9 (2000), 463-472.

[24] B.J. Yates, A.D. Miller and J.B. Lucot, Physiological basis and pharmacology of motion sickness: An update, Brain Res Bull 47 (1998), 395-406.

[25] M. Treisman, Motion sickness: An evolutionary hypothesis, Science 197 (1977), 493-495.

[26] G.R. Morrow, The effect of a susceptibility to motion sickness on the side effects of cancer chemotherapy, Cancer 55 (1985), 2766-2770. 
[27] J.F. Golding, Motion sickness, Handb Clin Neurol 137 (2016), 371-390.

[28] C.M. Oman, Are evolutionary hypotheses for motion sickness "just so" stories?, J Vestib Res 22 (2012), 117127.

[29] D.B. Tyler and P. Bard, Motion sickness, Physiol Rev 29 (1949), 311-369.

[30] A. Graybiel, B. Clark and J.J. Zarriello, Observations on human subjects living in a "slow rotation room" for periods of two days, Arch Neurol 3 (1960), 55-73.

[31] E.F. Miller and A. Graybiel, A provocative test for grading susceptibility to motion sickness yielding a single numerical score, Acta Otolaryngol Suppl 274 (1970), 1-20.

[32] A. Graybiel, C.D. Wood, E.F. Miller and D.B. Cramer, Diagnostic criteria for grading the severity of acute motion sickness, Aerosp Med 39 (1968), 453-455.

[33] P.J. Gianaros, E.R. Muth, J.T. Mordkoff, M.E. Levine and R.M. Stern, A questionnaire for the assessment of the multiple dimensions of motion sickness, Aviat Space Envir Md 72 (2001), 115-119.

[34] J.E. Bos, S.N. MacKinnon and A. Patterson, Motion sickness symptoms in a ship motion simulator: effects of inside, outside, and no view, Aviat Space Envir Md $\mathbf{7 6}$ (2005), 1111-1118.

[35] J.R. Lackner and A. Graybiel, Sudden emesis following parabolic flight maneuvers: implications for space motion sickness, Aviat Space Envir Md 57 (1986), 343-347.

[36] J.T. Reason and A. Graybiel, Changes in subjective estimates of well-being during the onset and remission of motion sickness symptomatology in the Slow Rotation Room, Aerospace Med 41 (1970), 166-171.

[37] J.F. Golding, A.C. Paillard, H. Normand, S. Besnard and P. Denise, Prevalence, predictors, and prevention of motion sickness in zero-g parabolic flights, Aerosp Med Hum Perf 88 (2017), 3-9.

[38] S.F. Wiker, R.S. Kennedy, M.E. McCauley and R.L. Pepper, Susceptibility to seasickness: influence of hull design and steaming direction, Aviat Space Envir Md 50 (1979), 1046-1051.

[39] B.D. Lawson and A.M. Mead, The sopite syndrome revisited: Drowsiness and mood changes during real or apparent motion, Acta Astronaut 43 (1998), 181-192.

[40] B.D. Lawson, Motion sickness scaling. Handbook of virtual environments: Design, implementation, and applications, 2nd Edition. New York, NY: CRC Press, an imprint of Taylor \& Francis Group, LLC. (2014), 601-626.

[41] B.D. Lawson and B.E. Riecke, The perception of body motion, ed. Stanney K., Hale K., Handbook of Virtual Environments: Design, Implementation, and Applications, CRC Press, New York, NY., 2014, 163-196.

[42] A. Bisdorff, M. Von Brevern, T. Lempert and D.E. Newman-Toker, Classification of vestibular symptoms: towards an international classification of vestibular disorders, J Vestib Res 19 (2009), 1-13.

[43] B.D. Lawson, A.H. Rupert and B.J. McGrath, The neurovestibular challenges of astronauts and balance patients: some past countermeasures and two alternative approaches to elicitation, assessment and mitigation, Front Sys Neurosci 10 (2016), 1-12.

[44] B.S.K. Cheung, I.P. Howard, J.M. Nedzelski and J.P. Landolt, Circularvection about earth-horizontal axes in bilateral labyrinthine-defective subjects, Acta Otolaryngol 108 (1989), 336-344.

[45] F. Murdin, F. Chamberlain, S. Cheema, Q. Arshad, M.A. Gresty, J.F. Golding and A. Bronstein, Motion sickness in migraine and vestibular disorders, J Neurol Neurosur Ps 86 (2015), 585-587.

[46] Y.H. Cha, R.W. Baloh, C. Cho, M. Magnusson, J.-J. Song, M. Strupp, F. Wuyts and J.P. Staab, Mal de Debarquement Syndrome Diagnostic Criteria: Consensus Document of the Classification Committee of the Barany Society, $J$ Vestib Res 30 (2020), 285-293.

[47] J.F. Golding, Motion sickness susceptibility questionnaire revised and its relationship to other forms of sickness, Brain Res Bull 47 (1998), 507-516.

[48] J.F. Golding, Predicting individual differences in motion sickness susceptibility by questionnaire, Pers Indiv Differ 41 (2006), 237-248.

[49] J.F. Golding and M. Kerguelen, A comparison of the nauseogenic potential of low-frequency vertical versus horizontal linear oscillation, Aerosp Med Assoc 63 (1992), 491-497.

[50] M.J. Griffin and M.M. Newman, Visual field effects on motion sickness in cars, Aviat Space Envir Md 75 (2004), 739-748.

[51] J.E. Bos, S.N. MacKinnon and A. Patterson, Motion sickness symptoms in a ship motion simulator: effects of inside, outside, and no view, Aviat Space Envir Md $\mathbf{7 6}$ (2005), 1111-1118.

[52] M.L. van Emmerik, S.C. de Vries and J.E. Bos, Internal and external fields of view affect cybersickness., Displays 32 (2011), 169-174.

[53] B. Keshavarz and H. Hecht, Validating an efficient method to quantify motion sickness, Hum Factors 53 (2011), 415-426.

[54] R.S. Kennedy, W.P. Dunlap and F. J.E., Chapter 11: Prediction of motion sickness susceptibility, G. H. Crampton, Boca Raton, FL., (1990), 179-215.

[55] S. Lamb and K.C. Kwok, MSSQ-Short norms may underestimate highly susceptible individuals: Updating the MSSQ-short norms, Hum Factors 57 (2015), 622-633.

[56] B. Keshavarz, R. Ramkhalawansingh, B. Haycock, S. Shahab and J.L. Campos, Comparing simulator sickness in younger and older adults during simulated driving under different multisensory conditions, Transport Res F-Traf 54 (2018), 47-62.

[57] R.S. Kennedy and J.E. Fowlkes, Simulator sickness is polygenic and polysymptomatic: Implications for research, Int J Aviat Psychol 2 (1992), 23-38.

[58] J.F. Golding and M.A. Gresty, Pathophysiology and treatment of motion sickness, Curr Opin Neurol 28 (2015), 83-88.

[59] B. Keshavarz and H. Hecht, Pleasant music as a countermeasure against visually induced motion sickness, Appl Ergon 45 (2014), 521-527.

[60] F.D. Yen Pik Sang, J.F. Golding and M.A. Gresty, Suppression of sickness by controlled breathing during mildly nauseogenic motion, Aviat Space Envir Md 74 (2003), 998-1002.

[61] D.B. Mowrey and D.E. Clayson, Motion sickness, ginger, and psychophysics, Lancet 1 (1982), 655-657.

[62] H.C.Lien, W.M. Sun, Y.H. Chen, H. Kim, W. Hasler and C. Owyang, Effects of ginger on motion sickness and gastric slow-wave dysrhythmias induced by circular vection, $A m$ J Physiol-Gastr L 284 (2003), G481-489.

[63] P.L. Palatty, R. Haniadka, B. Valder, R. Arora and M.S. Baliga, Ginger in the prevention of nausea and vomiting: a review, Crit Rev Food Sci Nutr 53 (2013), 659-669.

[64] A. Alkaissi, T. Ledin, L.M. Odkvist and S. Kalman, P6 acupressure increases tolerance to nauseogenic motion 
stimulation in women at high risk for PONV, Can $J$ Anaesth 52 (2005), 703-709.

[65] K.E. Miller and E.R. Muth, Efficacy of acupressure and acustimulation bands for the prevention of motion sickness, Aviat Space Envir Md 75 (2004), 227-234.

[66] A. Brainard and C. Gresham, Prevention and treatment of motion sickness, Am Fam Physician 90 (2014), 41-46.

[67] A. Shupak and C.R. Gordon, Motion sickness: Advances in pathogenesis, prediction, prevention, and treatment, Aviat Space Envir Md 77 (2006), 1213-1223.

[68] O. Samuel and D. Tal, Airsickness: Etiology, treatment, and clinical importance-a review, Mil Med 180 (2015), $1135-1139$.

[69] D.V. Sheehan, K. Harnett-Sheehan and B.A. Raj, The measurement of disability, Int Clin Psychopharm 11 (1996), 89-95.

[70] A.M. Bronstein, J.F. Golding, M.A. Gresty, M. Mandalá, D. Nuti, A. Shetye and Y. Silove, Validation of the Social life \& Work Impact of Dizziness questionnaire (SWID), 7th Meeting of the British Society of NeuroOtology, Leicester Tigers Rugby Stadium (2009).

[71] A.M. Bronstein, J.F. Golding, M.A. Gresty, M. Mandalá, D. Nuti, A. Shetye and Y. Silove, The Social Impact of Dizziness in London and Siena, J Neurol 257 (2010), 183-190.

[72] C.M. Reavley, J.F. Golding, L.F. Cherkas, T.D. Spector and A.J. MacGregor, Genetic influences on motion sickness susceptibility in adult women: A classical twin study, Aviat Space Envir Md 77 (2006), 1148-1152.

[73] I.F. Henriques, D.W. Douglas de Oliveira, F. OliveiraFerreira and P.M. Andrade, Motion sickness prevalence in school children, Eur J Pediatr 173 (2014), 1473-1482.

[74] B.S. Hromatka, J.Y. Tung, A.K. Kiefer, C.B. Do, D.A. Hinds and N. Eriksson, Genetic variants associated with motion sickness point to roles for inner ear development, neurological processes and glucose homeostasis, Hum Mol Genet 24 (2015), 2700-2708.

[75] M. Kluver, C. Herrigel, C. Heinrich, H. Schoner and H. Hecht, The behavioral validity of dual-task driving performance in fixed and moving base driving simulators, Transport Res F-Traf 37 (2016), 78-96.

[76] K.M. Stanney, R.S. Kennedy, J.M. Drexler and D.L. Harm, Motion sickness and proprioceptive aftereffects following virtual environment exposure, Appl Ergon 30 (1999), 27-38.

[77] S. Cobb, S. Nichols, A. Ramsey and J. Wilson, Virtual reality-induced symptoms and effects (VRISE), PresenceTeleop Virt (1999), 169-186.

[78] K. Stanney and G. Salvendy, Aftereffects and sense of presence in virtual environments: Formulation of a research and development agenda, Int J Hum Comput Interact 10 (1998), 135-187.

[79] A.C. Paillard, G. Quarck, F. Paolino, P. Denise, M. Paolino, J.F. Golding and V. Ghulyan-Bedikian, Motion sickness susceptibility in healthy subjects and vestibular patients: Effects of gender, age and trait-anxiety, $J$ Vestib Res $\mathbf{2 3}$ (2013), 203-209.

[80] J.O. Brooks, R.R. Goodenough, M.C. Crisler, N.D. Klein, R.L. Alley and B.L. Koon, Simulator sickness during driving simulation studies, Accident Anal Prev 42 (2010), 788-796.

[81] N. Kawano, K. Iwamoto, K. Ebe, B. Aleksic, A. Noda and H. Umegaki, Slower adaptation to driving simulator and simulator sickness in older adults, Aging Clin Exp Res $\mathbf{2 4}$ (2012), 285-289.
[82] S. Klosterhalfen, S. Kellermann, F. Pan, U. Stockhorst, G. Hall and P. Enck, Effects of ethnicity and gender on motion sickness susceptibility, Aviat Space Envir Md (2005), 1051-1057.

[83] P.M. Gahlinger, Cabin location and the likelihood of motion sickness in cruise ship passengers, J Travel Med 7 (2000), 120-124.

[84] D.A. Marcus, J.M. Furman and C.D. Balaban, Motion sickness in migraine sufferers, Expert Opin Pharmaco 6 (2005), 2691-2697.

[85] A. Lawther and M.J. Griffin, A survey of the occurrence of motion sickness amongst passengers at sea, Aviat Space Envir Md 59 (1988), 399-406.

[86] M. Turner and M.J. Griffin, Motion sickness incidence during a round-the-world yacht race, Aviat Space Envir Md 66 (1995), 849-856.

[87] J.F. Golding, P. Kadzere and M.A. Gresty, Motion sickness susceptibility fluctuates through the menstrual cycle, Aviat Space Envir Md 76 (2005), 970-973.

[88] J.F. Golding and M.A. Gresty, Motion sickness, Curr Opin Neurol (2005), 29-34.

[89] R.L. Matchock, M.E. Levine, P.J. Gianaros and R.M. Stern, Susceptibility to nausea and motion sickness as a function of the menstrual cycle, Womens Health Iss $\mathbf{1 8}$ (2008), 328-335.

[90] K. Meissner, P. Enck, E.R. Muth, S. Kellermann and A. Klosterhalfen, Cortisol levels predict motion sickness tolerance in women but not in men, Physiol Behav 97 (2009), 102-106.

[91] M.B. Flanagan, J.G. May and T.G. Dobie, Sex differences in tolerance to visually-induced motion sickness, Aviat Space Envir Md 76 (2005), 642-646.

[92] K.M. Stanney, K.S. Hale, I. Nahmens and R.S. Kennedy, What to expect from immersive virtual environment exposure: Influences of gender, body mass index, and past experience, Hum Factors 45 (2003), 504-520.

[93] S. D'Amour, J.E. Bos and B. Keshavarz, The efficacy of airflow and seat vibration on reducing visually induced motion sickness, Exp Brain Res 235 (2017), 2811-2820.

[94] D. Saredakis, A. Szpak, B. Birckhead, H.A.D. Keage, A. Rizzo and T. Loetscher, Factors Associated With Virtual Reality Sickness in Head-Mounted Displays: A Systematic Review and Meta-Analysis, Front Hum Neurosci 14 (2020), 96.

[95] K. Stanney, C. Fidopiastis and L. Foster, Virtual reality is sexist: but it does not have to be, Frontiers in Robotics and AI 7 (2020)

[96] H. Ujike, K. Ukai and K. Nihei, Survey on motion sickness-like symptoms provoked by viewing a video movie during junior high school class, Displays 29 (2008), 81-89.

[97] B. Keshavarz, A.C. Novak, L.J. Hettinger, T.A. Stoffregen and J.L. Campos, Passive restraint reduces visually induced motion sickness in older adults, $J$ Exp Psychol Appl 23 (2017), 85-99.

[98] J. Bos, W. Bles and E. Groen, A theory on visually induced motion sickness, Displays 29 (2008), 47-57.

[99] R.M. Stern, S. Hu, S.H. Uijtdehaage, E.R. Muth, L.H. $\mathrm{Xu}$ and K.L. Koch, Asian hypersusceptibility to motion sickness, Hum Hered 46 (1996), 7-14.

[100] B.S. Cheung, K.E. Money and I. Jacobs, Motion sickness susceptibility and aerobic fitness: A longitudinal study, Aviat Space Environ Med 61 (1990), 201-204.

[101] N. Rawat, C.W. Connor, J.A. Jones, I.B. Kozlovskaya and P. Sullivan, The correlation between aerobic fitness and 
motion sickness susceptibility, Aviat Space Envir Md $\mathbf{7 3}$ (2002), 216-218.

[102] F.F. Mo, H.H. Qin, X.L. Wang, Z.L. Shen, Z. Xu and K.H. Wang, Acute hyperglycemia is related to gastrointestinal symptoms in motion sickness: An experimental study, Physiol Behav 105 (2012), 394-401.

[103] A. Cuomo-Granston and P.D. Drummond, Migraine and motion sickness: What is the link?, Prog Neurobiol 91 (2010), 300-312.

[104] A.C. Paillard, G. Quarck, F. Paolino, P. Denise, M. Paolino, J.F. Golding and V. Ghulyan-Bedikian, Motion sickness susceptibility in healthy subjects and vestibular patients: effects of gender, age and trait-anxiety, $J$ Vestib Res $\mathbf{2 3}$ (2013), 203-209.

[105] A. Kayan and J.D. Hood, Neuro-otological manifestations of migraine Brain 107 (1984), 1123-1142.

[106] P.D. Drummond, Motion sickness and migraine: Optokinetic stimulation increases scalp tenderness, pain sensitivity in the fingers and photophobia, Cephalalgia 22 (2002), 117-124.

[107] J.M. Furman, D.A. Marcus and C.D. Balaban, Rizatriptan reduces vestibular-induced motion sickness in migraineurs. J Headache Pain 12 (2011), 81-88.

[108] D.A. Marcus and J.M. Furman, Prevention of motion sickness with rizatriptan: A double-blind, placebo-controlled pilot study, Med Sci Monit 12 (2006), PI1-7.

[109] J.M. Furman and D.A. Marcus, A pilot study of rizatriptan and visually-induced motion sickness in migraineurs, Int J Med Sci 6 (2009), 212-217.

[110] P.D. Drummond, Triggers of motion sickness in migraine sufferers, Headache 45 (2005), 653-656.

[111] W.H. Johnson, F.A. Sunahara and J.P. Landolt, Importance of the vestibular system in visually induced nausea and self-vection, J Vestib Res 9 (1999), 83-87.

[112] B.S. Cheung, I.P. Howard and K.E. Money, Visuallyinduced sickness in normal and bilaterally labyrinthinedefective subjects, Aviat Space Envir Md 62 (1991), 527-531.

[113] R.S. Kennedy, A. Graybiel, R.C. McDonough and F.D. Beckwith, Symptomatology under storm conditions in the north atlantic in control subjects and in persons with bilateral labyrinthine defects, Acta Otolaryngol 66 (1968), 533-540.
[114] J.F. Golding and M. Patel, Meniere's, migraine, and motion sickness Acta Otolaryngol 137 (2017), 495-502.

[115] J.D. Sharon and T.E. Hullar, Motion sensitivity and caloric responsiveness in vestibular migraine and Meniere's disease, Laryngoscope 124 (2014), 969-973.

[116] J.F. Golding, H.M. Markey and J.R. Stott, The effects of motion direction, body axis, and posture on motion sickness induced by low frequency linear oscillation, Aviat Space Envir Md 66 (1995), 1046-1051.

[117] S.H. Jeong, S.Y. Oh, H.J. Kim, J.W. Koh and J.S. Kim, Vestibular dysfunction in migraine: Effects of associated vertigo and motion sickness, J Neurol 257 (2010), 905-912.

[118] M. Dai, T. Raphan and B. Cohen, Prolonged reduction of motion sickness sensitivity by visual-vestibular interaction, Exp Brain Res 210 (2011), 503-513.

[119] M.E. Hoffer, K.R. Gottshall, R.D. Kopke, P. Weisskopf, R.J. Moore, K.A. Allen and D. Wester, Vestibular testing abnormalities in individuals with motion sickness, Otol Neurotol 24 (2003), 633-636.

[120] G. Clément and M.F. Reschke, Relationship between motion sickness susceptibility and vestibulo-ocular reflex gain and phase, J Vestib Res 28 (2018), 295-304.

[121] A. Shupak, D. Kerem, C. Gordon, O. Spitzer, N. Mendelowitz and Y. Melamed, Vestibulo-ocular reflex as a parameter of seasickness susceptibility, Ann Otol Rhinolo Laryngol 99 (1990), 131-136.

[122] D. Tal, D. Hershkovitz, G. Kaminski-Graif, G. Wiener, O. Samuel and A. Shupak, Vestibular evoked myogenic potentials and habituation to seasickness, Clin Neurophysiol 124 (2013), 2445-2449.

[123] T.A. Stoffregen, Y.C. Chen and F.C. Koslucher, Motion control, motion sickness, and the postural dynamics of mobile devices Exp Brain Res 232 (2014), 1389-1397. 